\title{
Editorial 25.2
}

\author{
Carmen Galán
}

Received: 26 March 2009/Accepted: 30 March 2009/Published online: 25 April 2009

(C) Springer Science+Business Media B.V. 2009

Dear readers,

Nowadays, people pay more and more attention to the environment. This fact is revealed by a major interest in green urban areas. This interest is not only related to the area's aesthetic value or its importance in the urban landscape, but also to its contribution to the quality of life of the citizens. When considering the health benefits of green urban spaces, people relate them to a more comfortable environment, and the possibility of practising physical activities, thus improving the urban quality of life. Nevertheless, when we study the role of the green urban spaces in improving this quality, it is necessary to pay special attention to public health by considering the possible presence of allergenic plants in those spaces. Today, an increase in pollen allergies among the population has been observed. This increase is more prevalent in urban inhabitants than rural ones. This can be due to different factors, but here I will discuss the lack of biodiversity in flora in recent green urban spaces.

The ancient urban green spaces usually contained a notably rich biodiversity, where not only ornamental species, but also cultivated and spontaneous species, from different origins were represented. This special urban design, the surrounding landscape and

C. Galán $(\bowtie)$

Department of Botany, Ecology and Plant Physiology, University of Córdoba, Campus Universitario Rabanales, Córdoba, Spain

e-mail: bv1gasoc@uco.es crops defined the particular urban flora that characterized old cities. However, recent urban growth, with uncontrolled expansion creating urban sprawl in some places, is provoking an environmental biodiversity impoverishment. The current trend towards the creation of new urban areas of low density is generating the need for special infrastructures to facilitate citizen mobility, thus affecting the fragmentation of the natural spaces and, in general, affecting the landscapes. In considering this matter, it would be better to propose a compact city design, with wider green spaces, as a sustainable urban form. This type of city can offer clear advantages, not only from an economic and social point of view, but also in benefiting the environment. However, as we know, this proposal also brings debate among the defenders and the detractors.

Many green urban designs today try to include plants better adapted to the special urban microclimatic conditions under the different architectonic and ecological characteristics that define today's cities. Taking into consideration the special characteristics of the new urban expanded model in some regions, only some species can support this kind of urban pressure. In some cities the same species is present in different neighbourhoods, offering a lack of diversity in the urban landscape. If these selected species produce allergenic pollen grains, such as species from Cupressus or Platanus, they are responsible for higher pollen-related allergies among the population, related to their (over-)abundance in some cities. On 
some occasions these introduced and well-adapted species can even adopt invasive activity, such as in the case of different Ligustrum species in some places.

On the other hand, besides the ornamental plants that characterize the urban landscape, it is important to consider some spontaneous natural plants that colonize urban areas. They try to colonize new spaces by developing their own ecological niches. An example is Parietaria, which grows even in old walls and ruins, and is one of the main causes of pollen allergy in some places in the Mediterranean region. Another important example is Ambrosia artemisifolia, an invasive species introduced in Europe and responsible for a high incidence of pollen allergies in different areas of Eastern Europe.

For this reason, it is important to design a city model that would promote urban green space biodiversity and to recommend to the urban designers to take advantage of this new city model to forward the use of a more diverse number of species, thus enhancing the quality of life. 